\title{
A comparative evaluation of models of lactating ruminant
}

\author{
D Sauvant \\ Laboratoire INRA-INAPG de Nutrition et Alimentation, 16 rue Claude Bernard, Paris Cedex 05, France
}

\begin{abstract}
Summary - Nutrition of lactating ruminant has been the aim of several mathematical models for several decades. A comparative study of these models was performed on a limited number of aspects. At the digestive level certain models were based on compartmental structure while others were built on stretched flows ones. Only few systematic comparisons of the models of digestion have already been carried out and it appears necessary to achieve a more detailed level of comparison. On some important aspects, the level of knowledge, and therefore the reliability of digestive models, remains largely unsufficient. This is particularly the case of the production and absorption rates of volatile fatty acids in the reticulo rumen. Quantitative knowledge remains also unsufficient on the absorbed flows of glucose and long chain fatty acids in the small intestine. On metabolic aspects the already published or used models are also largely different one from each others. The level of aggregation, which can be roughly evaluated with the number of tissular and metabolic compartments differs largely between models. This number ranges from LT 10 to more than 50 for research models. Another important feature on which models largely differ concerns the regulating system. It was in all models more or less theoritical due to the lack of knowledge to elaborate a mechanistic model of regulations. Otherwise the published regulating systems took into consideration at various degree the homeostatic and homeorhetic drives. The comparison of the existing models of lactating ruminant was also reviewed through the major organs (splanchic area, liver, protein, lipids, udder) and metabolic areas (metabolism of nitrogen, lipids and minerals).
\end{abstract}

\section{Introduction}

Nutrition of lactating ruminant has been since the turn of the previous century a topic of research. A major target and application of this research has been the development of feed unit systems. Numerous systems have been thus successively proposed, each one being more accurate than the previous one. For each limiting nutrient the common aim of these systems was to predict, in a same set of additive units, the animal requirements from performances, and the feedstuffs values from chemical analysis.

This classical approach of "meeting the requirements" is changing rapidly because animal production has been progressively faced to new challenges such as diet optimisation in a context of milk quotas, environmental concerns, product quality, animal health and welfare... These challenges have strengthened the opportunity of predicting animal responses to diet variations (Sauvant, 1992). Such conceptual revolution, or new paradigm, in applied animal nutrition can be largely helped by the progresses in modelling. This is particularly relevant for lactating ruminants because of their economical importance and their biological particularities. For these reasons, lactating ruminant have taken a large place in development of mathematical modelling in animal nutrition for more than 25 years.

Numerous empirical models dealing with input (feed) output (milk production) relationships have already been published. They will not be considered in this report although several of them are of high practical interest. In this report, our interest was only focused on whole animal mechanistic models. They have been published during the last decade (Baldwin et al, 1987, 1995; Paul 1990; Danfaer, 1990). Some other models have been built and used to help experimental research although only partially published as the lactating ruminant model developed in our lab (Sauvant and Phocas, 1993; Sauvant et al, unpublished).

The aim of this report was not to do a systematic comparison of these whole animal 
models which would constitute a huge work. The purpose was to focus on some specific underlying aspects which seemed to us essential and on which model proposals differ.

\section{Modelling digestive processes as an input subsystem to the whole animal model}

\section{General principles}

During the last three decades several mechanistic models of ruminant digestion were published and/or used. Their mechanisticity was based on the fact that they did not consider the rumen or the digestive tract as a "black box" by taking into account some underlying events of digestion. Among these models a distinction can be made between the "stretched flows" ( «flux tendus" in French) and the "compartmental" models. A compartmental rumen model is a representation of these systems through their main underlying entities (substrates, microbes, and products...) which are considered as compartments. Such models have to be preferred if the dynamic variations in size of the compartments are meaningful according to the aim of the model. This are typically the case of short term (i.e. minute scale) digestive processes which could influence intake regulation (Sauvant et al, 1996). In contrast if the time scale is larger, for example 24 hours, short term variations in size of the compartments can be neglected, they become thus «zero pool compartments» and the model was then called a stretched flows one. In modelling the whole nutrition of lactating ruminant, if the purpose is a daily basis and a practical use, it seems necessary to study carefully the respective advantages and drawbacks of these two types of model.

\section{Prediction of absorption flows of amino acids}

Stretched flow models, built through empirical approaches, were used in the modern protein feed unit systems which were published in most of the European countries (Madsen, 1985; Vérité et al, 1987; AFRC, 1992...). All these models were conceptually similar, however differences of values in their basic items could lead to some variations in the predicted flows of amino- $\mathrm{N}$ at the duodenum or absorbed through the small intestine wall (Verité and Peyraud, 1994). In many protein unit systems the microbial protein production was predicted with a linear relationship from the calculated fermentable organic matter, (Vérité et al, 1987; table I) or energy (AFRC, 1992). However several works carried out on literature data bases underlined the existence of a linear influence of dry matter intake (DMI) and a curvilinear influence of the concentrate proportion on the microbial production efficiency (Archimede et al, 1996). Such discrepancies could obviously be a major drawback for modelling lactating ruminant nutrition.

Several comparisons of rumen models were already published (Bannink and de Visser, 1995; Kohn et al 1995). Ramangasoavina and Sauvant (1993) have observed that a validation procedure of one compartmental (Baldwin et al, 1987), one stretched flow (French PDI system, Verité et al, 1987) and an intermediate model (Cornell model, Fox et al, 1988) led to approximately the same conclusions. They were unable to simulate accurately the experimental variability of rumen microbial proteosynthesis as it appeared through a literature data base. A report, from the same issue aimed to compare rumen models (Dijkstra and France, 1995) underlines that large differences can be observed between the current rumen mechanistic models particularly on aspects dealing with particle kinetics.

Otherwise differences appeared also in the prediction of lysine and methionin flows between the PDI (Rulquin et al, 1993) and Cornell (O'Connor et al, 1993) systems. It is therefore hopeful to perform a careful comparison of these two approaches and of mechanistic models (Lescoat and Sauvant, 1995) carried out on trials which have highlighted the limiting role of at least one of these two amino acids.

\section{Prediction of absorption flows of VFA}

If several systems to predict protein and amino acids absorbed flows are now available, this is not the case of the volatile fatty acids (VFA). The VFA represent around $2 / 3$ of the apparently absorbed energy in ruminant. Furthermore it is now well documented that rumen VFA profile variations can influence energy partition into the body and therefore 
Table I. Simple methods of calculation of the flows of VFA absorption in ruminant.

Method 1 (inspired from Thivend, Poncet 1978)

$$
\begin{aligned}
& \text { INC2 }=\text { DOMI } *(-174 * \text { OMD }+20.57) \\
& \text { INC3 }=\text { DOMI } *(0.022 * \text { OMD }+0.20)
\end{aligned}
$$

Method 2

a- Prediction of rumen VFA concentration from diet ( literature data base of Munoz et al 1995)

$$
\begin{aligned}
& \mathrm{CAC}=93.30-15.65 \mathrm{C}^{2}+0.36 *(\mathrm{OMI} / \mathrm{MLW}) \\
& \mathrm{CPR}=29.41+26.02 \mathrm{C}^{2}+0.23 *(\mathrm{OMI} / \mathrm{MLW}) \\
& \mathrm{CBU}=30.90+45.4 \mathrm{C}-31.6 \mathrm{C} 2 \\
& \mathrm{CMI}=4.1+6.0 \mathrm{C}^{2}+0.16(\mathrm{OMI} / \mathrm{MLW})
\end{aligned}
$$

b- Prediction of VFA flows of absorption from CAC, CPR, CBU, and CMI and the equations of Dijkstra el al (1993) based also on rumen volume and $\mathrm{pH}$

\section{Method 3}

a- Assumption that 9 mol of VFA are produced per $\mathrm{kg}$ of organic matter fermented in the rumen (values from 7 to 11 in the literature)

b- assumption that the profile of VFA production is similar to the profile of VFA proportion in the rumen

\section{Method 4 (mean values of published data on short chain acid portal flows)}

a- assumption that $35 \%$ of entering metabolisable energy is from $\mathrm{C}_{2}$ and $\mathrm{C}_{4}$ acids

b- assumption that $20 \%$ of entering metabolisable energy is from $\mathrm{C}_{3}$ acids

\section{Method 5}

Prediction of INC2 and INC3 from equations calculated by Ortigues (1994) from a literature data base. The predictive variables are live weight, metabolisable energy intake, diet crude fibre and crude protein contents

\section{Legend}

INC2: input of $\mathrm{C}_{2}$ and $\mathrm{C}_{4}$ acids $\left(\mathrm{m} \mathrm{mol}_{2}\right.$ )

INC3: input of $\mathrm{C}_{3}$ acids ( $\mathrm{m} \mathrm{mol} \mathrm{C}_{3}$ )

DOMl: digestible organic matter intake $(\mathrm{g} / \mathrm{d})$

OM: diet organic matter digestibility $(\%)$

OMI: organic matter intake $(\mathrm{g} / \mathrm{d})$

MLW: metabolic live weight $(\mathrm{kg})$

$C$ : concentrate proportion in the diet $(0<C<1)$

$\mathrm{CAC}, \mathrm{CPR}, \mathrm{CBU}, \mathrm{CMI}$ : ruminal concentrations of acetate, propionate, butyrate and minor VFA (mmol/l) 
milk fat content. To illustrate the uncertainty of knowledge on ruminal VFA production and profile, the table I presents 5 simple methods of calculation of the flows of absorption of $\left(\mathrm{C}_{2}+\mathrm{C}_{4}\right)$-chain (acetate, butyrate, $\mathrm{B}-\mathrm{OH}$ butyrate, aceto-acetate) and $\mathrm{C}_{3}$-chain (propionate, lactate) acids. Figures 1 and 2 show data of the simulations of the flows of absorption of these two aggregated nutrients for a dairy cow producing $30 \mathrm{~kg}$ milk at the peak of lactation. These figures stress several important aspects : -the simulated values of these flows of VFA can vary from 1 to 2 depending on the methods;

-the ranking order of the methods is not the same for the $\left(\mathrm{C}_{2}+\mathrm{C}_{4}\right)$ and $\mathrm{C}_{3}$ type of chains;

Other large discrepancies between these five methods were observed. This is the case of the VFA profile of absorption when the proportion of concentrate is changed in the diet: in contrast of method 4, the methods $1,2,3$ and 5 allow a VFA profile variations. Another method of VFA production, not included

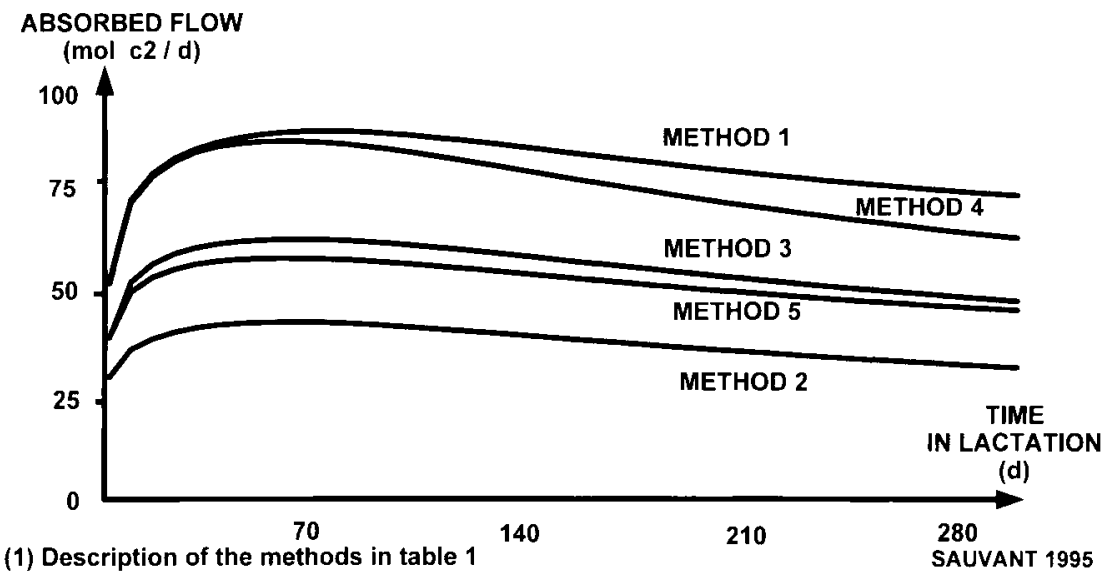

Figure 1. Comparison of several methods of prediction of the absorbed flows of $C_{2}$ and $C_{4}$ short chain fatty acids in dairy cows.

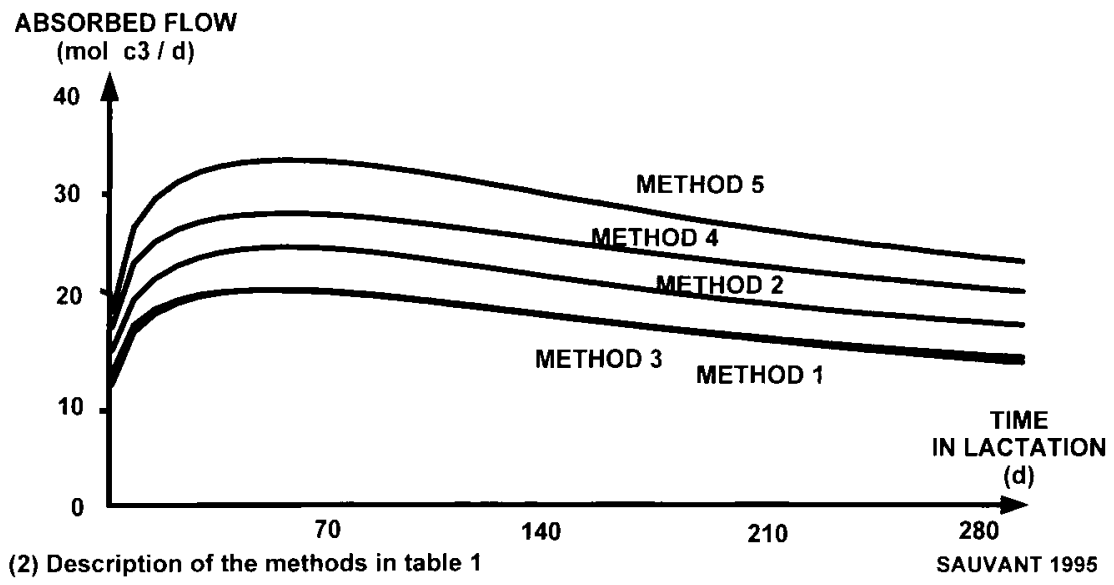

Figure 2. Comparison of several methods of prediction of the absorbed flows of $\mathrm{C}_{3}$ short chain fatty acids in dairy cows. 
because based on a more detailed description of the diet composition, has been proposed by Murphy et al (1982). Their equations were used in several mechanistic rumen models (Baldwin et al 1987; Danfaer 1990; Dijkstra et al, 1992). These authors have stressed the lack of reliability of this method, specifically for diets rich in concentrates .

These observations and the results of current simulations indicate thus that one of the major limit of accuracy in modelling dairy ruminant metabolism is the dramatic lack of validated method in predicting VFA production and absorption. It can be expected that recently and future published data on VFA portal flows will provide a sound basis of validation of various models of VFA production and absorption.

\section{Prediction of flows of glucose and fatty acid absorption}

It is nowadays not relevant to build model of the nutrition of lactating ruminant without considering glucose and long chain fatty acid absorption flows. The models of Baldwin et al, (1987) and Danfaer (1990) have taken mechanistically these aspects into account. However, they have not been validated in details on these aspects. Therefore it could be relevant to use, in a first step of modelling, the empirical modular methods of calculation proposed by Sauvant et al (1994) and of Doreau and Ferlay (1994) to respectively predict the glucose and fatty acid absorption flows in the small intestine. These two approaches present the advantage to have taken into account literature data on duodenal flows of starch and fatty acids respectively. Systematic assessments of the available empirical or mechanistic models to predict glucose and fatty acid absorption in lactating ruminants need to be carried out.

\section{Prediction of rumen volume}

Even some simple basic information on rumen characteristics does not seem until now well predicted in digestive models. This is the case of the rumen volume (RV). RV can largely vary along the lactation and also between individuals. The importance of RV in determining intake capacity (Forbes, 1995) and VFA production and flows of absorption (Dijkstra et al 1993) has already been put in evidence. Several empirical equations are currently available to predict RV from animals and diet parameters (Table II). Figure 3 shows how these equations can lead to large discrepancies in RV pattern of a "standard cow" during the lactation.

Table II. Empirial equations to predict rumen volume (RV) in dairy cows.

1. Owens and Goetsch (1986)

$$
\mathrm{RV}=18.4-6.21 * \mathrm{DMl}+2.45 * \mathrm{DMl} 2 \quad(\mathrm{n}=49, \mathrm{R} 2=0.25)
$$

$$
(\% \text { LW) }
$$

2. Remond (1988)

$$
\mathrm{RV}=2.26 *(\mathrm{DMl} / 1000)+40.5
$$

(I) $\quad(\mathrm{kg} / \mathrm{d})$

3. Bosch (1991)

$R V=(0.024 * F C M+0.014 * N D F R+0.10 * C-0.010 * L W) / 120$

(I)

4. Paul (1990)

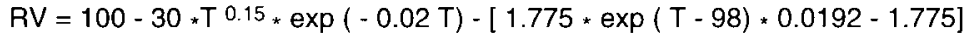

(l)

\section{Legend}

LW: live weight $(\mathrm{kg}), \mathrm{DMl}$ : dry matter intake $(\mathrm{kg} / \mathrm{d}), F C M$ : fat corrected milk $(\mathrm{g} / \mathrm{kg} \mathrm{MLW})$, NDFR: forage NDF content ( $\mathrm{g} / \mathrm{kg} \mathrm{DM}), \mathrm{C}$ : proportion of concentrate $(\%), \mathrm{T}$ : days in milk 


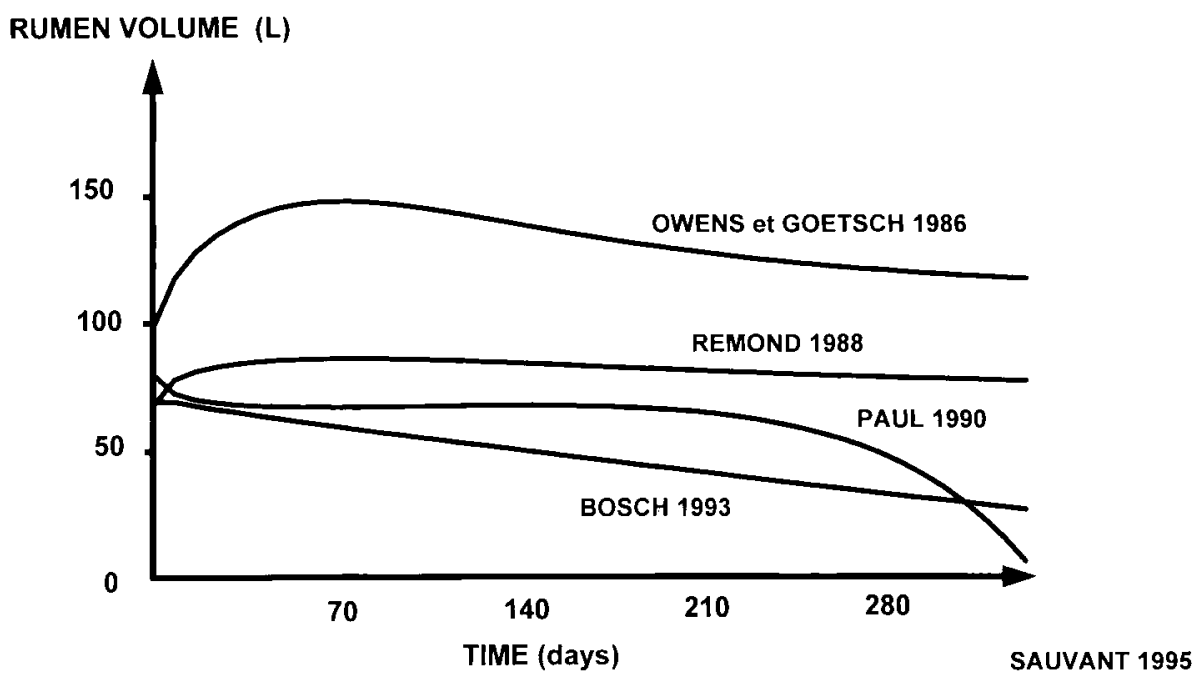

Figure 3. Simulation of rumen volume evolution in lactating dairy cow.

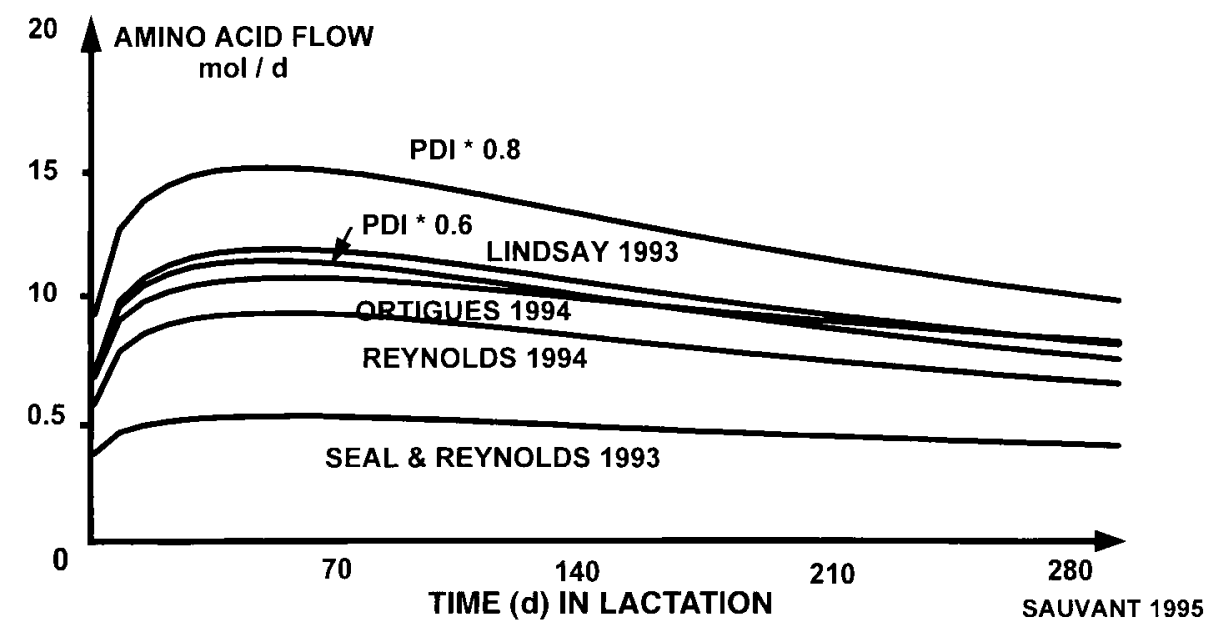

Figure 4. Comparison of several methods of prediction of the absorbed flow of amino acids in dairy cow. 


\section{Nutrient metabolisation through the gut wall}

There is no published mechanistic model of gut wall metabolism despite its importance in determining the quantitative flows of nutrients. An example of the impact of values of nutrient metabolisation by the gut wall is shown in Figure 4 . It depicts the consequences of varying this level from 0.2 to 0.4 when total amino $\mathrm{N}$ portal flow is predicted with the model of PDI system for a diet having $16 \%$ of crude protein in dry matter. The comparisons of the simulated values with data obtained from 4 published empirical equations (Seal and Reynolds, 1993; Lindsay, 1993; Ortigues and Visseiche, 1995; Reynolds, 1995) show that :

- large differences are observed between these 4 empirical published equations that were all based on experimental data;

- the coefficient of nitrogen metabolization by the gut wall seems high, may be larger than 0.4 as already suggested by data of Reynolds et al (1993);

These results underline the need to do a prioritary research effort on the gut wall quantitative metabolism of terminal products of digestion.

\section{Modelling metabolic processes of lactation}

\section{Choice of a level of aggregation}

It is important to have the least complicated structure which allows to achieve the purpose of a lactating ruminant model. Therefore higher levels of aggregation have to be preferred, at least at the first step of development of a model. Some basic comments about the level of aggregation of metabolic models have to be done:

Research models tend to contain more compartments and connecting pathways to try to mimic more precisely the reality as it appears through experimental data. In this context, on the basis of the number of tissular (NCt) and metabolic ( $\mathrm{NCm}$ ) compartments it can be said that the models of Danfaer (1990; NCt $=4$ and $\mathrm{NCm}=53$ ) and Paul (1990; $\mathrm{NCt}=7$ and $\mathrm{NCm}=60$ ?) are devoted to research while those of Baldwin et al (1987, $\mathrm{NCt}=3$ and $\mathrm{NCm}=4$ ) and Sauvant et al (unpublished, $\mathrm{NCt}=3$ and $\mathrm{NCm}=5$ ) are more extension-oriented.
The choice of a level of aggregation concerns not only structures and functions but also the time step. On this standpoint it is usually stated that lowering the level of aggregation of a system necessitates to decrease consistently the length of the basic time step. The reciprocal principle is also relevant. Classically the basic time step applied in animal nutrition was of 24 hours. It seems necessary to choose time steps shorter than $24 \mathrm{~h}$ only for specific purpose such as simulating milk fat content variations related to feeding frequency. However reducing the time step of a model would not automatically lead to a better accuracy in predicting lactating ruminant responses to diets.

The activity consisting in simplification by aggregation of research models without loosing their ability to predict responses to diets will likely become an increasing challenge in the future. In this context, as for digestion modelling, there is a debate on the choice between compartmental and stretched flows models. The mechanistic models of lactating ruminant have actual compartments but also some zero pool compartments assuming thus stretched flow sub-structures. For instance the models of Baldwin et al (1987) and Sauvant et al (unpublished), which have both few metabolic and tissular compartments, contained also respectively 8 and 2 zero pool compartments.

\section{Modelling regulations of lactation}

\section{Systemic approach of the organism}

The organism can be seen as a biological system characterized by a high level of complexity and control (Sauvant, 1992). At its highest level of aggregation this system can be divided into two subsystems (Sauvant, 1994).

The operating subsystem (OS) constituted by a complex hierarchy of compartments connected by pathways. The first level of organisational hierarchy within OS is the distinction between the digestive and metabolic subsystems.

The regulating subsystem (RS) which is a part of the whole endocrine control system. On nutritional as in other aspects living organisms are regulated to achieve two major purposes (see the teleonomic project of Monod, 1970) : their own survival and the perennity of their species. The homeostatic regulations (HS) aim at the first target while the homeorhetic 
regulations (HR) concern the second one. $A$ discussion on these regulations and the way to model them was published by Sauvant (1994). Consequently only some basic or new aspects are considered here.

\section{Homeostatic regulations}

In nutrition, HS act mainly as a buffer allowing to smooth the short term failures of adjustment between irregular inputs of nutrients and their chronic demand driven by HR. That means that HS have to control two kinds of opposed metabolic situations, shortage and excess of nutrients in comparison with the instantaneous tissular requirements. Therefore, according to this scope HS has to be short term reactive and is essentially concerned by non steady state metabolic conditions. This last statement indicates that modelling HS situation must to be based on compartmental systems. The non steady state situation can lead to complicated problems of modelling dynamic non linear and unstable systems (Goldbeter 1990). Furthermore, from the modelling point of view at least two types of homeostasis have to be distinguished according to the level of control. It is proposed to call them passive and active homeostasis.

The HS regulations of some metabolic routes appear as «passive" or non regulated. In this case, transfers of nutrients between compartments are essentially driven by the mass action law, without a central and specific RS. Therefore the efficiency of such HS regulations is largely depending on the structural combination of the involved compartments (number of intermediary compartments, possibility of retroactive flows of matter, differences in volumes and turn over rates from one compartment to another...). This type of HS regulation is particularly efficient to smooth the kinetics of nutrients entry and to adjust therefore better to the continuous cellular demands. As an example, the metabolism of $\mathrm{NH}_{3}$ and urea is known to follow largely this type of $\mathrm{HS}$ regulation. In this context liver steatosis can also be seen as a compartment of delay between the irregular NEFA release by adipose tissues and the mammary demand for a continuous milk fat synthesis process. Otherwise it can be presumed that some metabolic cycles which could appear as "futile" in a static approach could take all their usefulness when considered at the dynamic homeostatic point of view (i.e. the glucose-lactate cycle between organs).

In contrast, other metabolisms are tightly and specifically controlled by the $\mathrm{HS}$ regulating subsystem. The major example of such active $\mathrm{HS}$ is the short term regulation of energy metabolism which implies nutrients (propionate, glucose, lactate, glycerol, NEFA...) and hormones (insulin, glucagon, epinephrine...). In such situation the HS system receives informations concerning the OS status (i.e. plasma glucose content). These informations are treated by the HS regulating system which responds with "orders" resulting, in alterations of the rates of one or several flows or fluxes of nutrients.

For practical purpose opportunity to model $H S$ regulations appears when they are involved in determining the animal responses to diet. For instance, the influence of feeding frequency on the milk fat content suggests to model the energy HS system. Another example is the influence of the level of short term lipomobilisation on intake regulation (Bareille et al, 1996). Modelling the energy HS system is greatly facilitated by the fact that the short term variations of the plasma concentrations of the major involved hormones generally present a biological meaning. Therefore it was possible to model through a compartmental structure the key nutrients and hormones of the energy HS system and to check its dynamic properties through metabolic responses to challenges of nutrients (propionate, glucose) or hormones (glucose, glucagon) (Sauvant and Grizard, 1992 and unpublished). However, as such this model remains too simple and isolated to achieve the above mentioned practical purpose. To reach this target, it would be necessary to simultaneously model short term variations of intake rate, of ruminal digestion and of metabolic partition of nutrients between udder and adipose tissue.

The models of Baldwin et al (1987) and Danfaer (1990) did not include explicitly an active HS subsystem. However glucose was the central point of energy regulation (see further) of the Baldwin's model. As the compartmental structure of its rumen submodel allowed to tackle short term variations a validation of the metabolic part of this model could be performed in post prandial conditions with 2 meals/d (Baldwin et al, 1987). The Danfaer's model was also checked under non continuous feeding conditions. Digestive and metabolic simulated consequences were 
discussed (Danfaer, 1990). It appeared that, from one hand, the variations of the concentrations of insulin and glucagon were induced by the pattern of entry of nutrients and, from the other hand, the metabolic effects of these hormones on peripheric tissues allowed to achieve a fairly realistic homeostatic behaviour of the model. The detailed mechanistic model of Paul (1990) was essentially built and run in the short term conditions ranging from 1 to $10 \mathrm{~h}$ after a meal. By this way, this model appears to be an interesting tool to explore and check the behaviour of the HS regulations in lactating ruminants.

Because of its complicated behaviour the assessment of the energy HS model must particularly be complete and careful. It is thus necessary to check it in all the known possibilities of validation. This was not yet performed by the above mentioned models. For instance none of them has already been evaluated in situation of phlorizin supply which is known to largely increase the urinary glucose sink. Otherwise the models of Baldwin et al (1987), Danfaer(1990) and Paul (1990) have neglected the negative retroactive influence of the energy HS status on intake (satiety). This last aspect was one of the major target of the short term model of intake regulation recently published by Sauvant et al (1996).

For a practical and a modelling purpose it must be kept in mind that the HS role is determinant in partitioning nutrients having a dynamic pattern of entry. This is particularly the case of $\mathrm{NH}_{3}$ and short chain fatty acids issued from ruminal digestion. In turn nutrients which are absorbed at the intestinal level (i.e. amino acids and long chain fatty acids) have a largely smoothed pattern of entry. Therefore their entry rate is closer to the utilization one of the tissues. The issue is then to evaluate the opportunity to consider a submodel for HS regulation for these metabolites.

\section{Homeorhetic (or teleophoretic) regulations (Table III)}

HR regulations traduce "orders" which are directly translated from the genome to ensure a control of metabolism in support of pregnancy and lactation (Bauman and Currie, 1980). Knowledge on the endocrinological aspects which are involved in HR regulation have strongly increased during the last decades.
However, these regulations are so complex that quantitative knowledge remains far from being sufficient to elaborate a mechanistic and realistic model of $\mathrm{HR}$ regulations in lactating ruminants. Therefore until now, only theoretical, and thus non satisfactory, solutions were proposed to model HR regulations of lactation.

The first attempt to model HR in lactating ruminant was proposed by Baldwin et al (1987). In this work, actual glycemia [GL] was considered as the major index of energy status and hormonal activities. More precisely the ratio of a standard glycemia ([GLo] $=3.10^{-3}$ mole/l) to actual glycemia was taken as an index of catabolic hormone $(\mathrm{CH}=[\mathrm{GLO}] /[\mathrm{GL}])$. A biological analogy can be found between this $\mathrm{CH}$ and the concept of "lactation hormone" in the simple lactation model of $\mathrm{Neal}$ and Thornley (1983). The influence of $\mathrm{CH}$ on the catabolic tissular pathways uses various forms of equations according to the tissues (Table III). The biological background of the mathematical expression of the of $\mathrm{CH}$ influence did not clearly appear in Baldwin et al (1987). For all pathways involving glucose as a cosubstrate there was a sigmoidal influence of $[\mathrm{GL}]$ on the flow rates (Table III). For anabolic activities the Michaelis constant was proportional to $\mathrm{CH}$ while for the catabolic flow it was the maximum value of the flow which was influenced by $\mathrm{CH}$. Recently, Mc Namara and Baldwin (1995) discussed the ways to improve the connection between the glucose linked hormonal factors and the metabolic flows to adipose tissue.

In the model of Danfaer (1990) the plasma contents of growth hormone (GH), insulin (INS) and glucagon (GLA) are used as driving variables. One problem raised by this statement is to have a base of experimental data of plasma concentrations of these 3 hormones corresponding specifically to HR, and not HS, regulations. Moreover these concentrations have to be able to cover a broad range of genotypes and of lactation stages. Danfaer (1990) has used the data of Herbein et al (1985) which were statistically adjusted with milk yield, live weight and days in lactation. In this model the $[\mathrm{GH}]$ presented a linear decrease along the lactation and it influenced the udder uptake rate of all the metabolites except triglyceride fatty acids. The anabolic pathways of adipose and lean tissues were positively related to [INS]. The hormonal regulation of catabolism only concerned 
adipose tissue mobilization which was negatively related to [INS]. Therefore, the pattern of the partition of nutrients and the metabolic harmonisation between body tissues and mammary metabolism was achieved by opposite trends of evolution in time between [GH] and [INS]. In this model there was also a specific regulation of liver metabolism consisting in an influence of the [GLA]/[NS] ratio on several pathways: gluconeogenesis, ketogenesis, amino-acid uptake and desamination. A major limit of this model is that its driving force is linked to hormones which concentrations in the blood have a very limited or imprecise biological meaning. Furthermore two of them, insulin and glucagon are documented to be more involved in homeostatic than homeorhetic regulation.

Sauvant and Phocas (1993) have also proposed to model HR regulation of lactating ruminant with a theoretical HR system. This HR submodel integrated well known principles in a quantitative form. It was based on two theoretical aggregated hormonal effects of anabolism $(\mathrm{AH})$ and catabolism $(\mathrm{CH})$ which are entirely linked by an hyperbolic relation $(\mathrm{CH}$ * $\mathrm{AH}=0.1$ ). This equation expressed that anabolism and catabolism are almost exclusive activities into an organism, as it was shown by Chilliard and Robelin (1985) in a study of lipid metabolism of lactating cows. $\mathrm{CH}$ was assumed to present an exponential decay along the lactation: $\mathrm{CH}=\mathrm{a}+\mathrm{b} * \exp (-\mathrm{c} *$ time $)$. The parameter $\mathrm{a}, \mathrm{b}$ and $\mathrm{c}$ were related to the potential of milk production $(\mathrm{POT}=$ maximum milk yield/10) which depends on genotype and age. The assumption of an exponential decay of an hormonal action in lactating animals already existed in the model of $\mathrm{Neal}$ and Thornley (1983). However, it was only to simulate the known evolution of the milk yield during the lactation. This regulating HR system based on $\mathrm{AH}$ and $\mathrm{CH}$ values determined by POT, was connected with the metabolic inflows

Table III. Ways of integration metabolic regulation in some metabolic models of lactation.

$$
\begin{aligned}
& \text { References } \\
& \text { Baldwin et al. (1987) } \\
& \text { Danfaer (1990) } \\
& \text { Sauvant et Phocas (1993) } \\
& \text { Anabolism } \\
& \begin{array}{l}
U=V m\left(1+\frac{k C H}{|S|}\right)^{-1} \\
S=F a, A a, A c,
\end{array} \\
& \text { 1) } U=\left.\eta i N S\right|^{*}\left(1+\frac{k}{|S| \times S_{Z}}\right) \\
& \mathbf{U}=\mathbf{f}(\mathbf{A H}) \text { * }|\mathbf{S}| \text { * } \mathbf{S z} \\
& \mathrm{S}=\mathrm{Aa}, \mathrm{Gl}, \mathrm{Fa}, \mathrm{Ac}+\mathrm{Kt} \\
& S=A c+B u, A a, G l, T s \\
& \text { 2) } U=\{|I N S| \text { * }[S] \\
& S=A c+K t \\
& \text { 1) } U=r(C H) *\left(1+\left(\frac{k}{[S]}\right)\right)^{-1} \\
& \mathbf{S}=\mathbf{T s} \\
& \begin{array}{l}
U=f[I N S] *\left(1+\frac{k}{|S| \times S_{Z}}\right)^{-1} \\
S=T g
\end{array} \\
& \mathrm{U}=\mathrm{I}(\mathrm{CH}) \text { * }|\mathrm{S}| \text { * } \mathrm{Sz} \\
& \text { 2) } \mathrm{U}=\mathrm{f}(\mathrm{CH}) *([\mathrm{~S}]) \\
& \mathbf{S}=\mathbf{P b}, \mathbf{P v} \\
& \mathrm{S}=\mathrm{BP}, \mathrm{Ts} \\
& \text { 1) } U=f|G H| *\left(1+\frac{k}{|S| \times S_{Z}}\right)^{-1} \quad U=f(C H) *|S| * M F * U R \\
& S=G l, A a \\
& S=A a, A c+B u, F a, T s \\
& \text { 2) } U=r|G H| \times|S| \\
& S=A c+K t
\end{aligned}
$$

$\mathrm{U}$ : flux rate; Vm: maximum flux rate; [S]: substance concentration; Sz: size of the compartment; MF: mammary blood flow; UR: mammary uptake rate; Ac: acetate; Bu: butyrate; Kt: Ketones; Gl: Glucose; Fa: NEFA; TS: triglycerides; At: ATP; Aa: amino acid; Ly: lysine; BP: body proteins; Pv: viscera proteins; $\mathrm{Pb}$ : lean proteins; ND: not determinant. 
and outflows of two compartments of body tissues (adipose and protein) and with the levels of dry matter intake and lactose secretion. The parameters of the equations dealing with the influence of $\mathrm{CH}$ on metabolic flows were determined by empirically fitting the evolution of the body composition of the dairy cow published by Belyea et al (1978). A determination of numerical values of key items from only one experimental data source was obviously one of the weaknesses of this model. For pattern of lactose yield, the parameters values originated from fitting lactation curves published by Faverdin et al (1987) by a gamma function integrating the item POT and assuming a constant lactose content of $48 \mathrm{~g}$ per $\mathrm{kg}$ of milk. In this model the mammary glucose demand was a metabolic priority which was directly driven through stretched flows by the lactose yield. The DMI pattern was calculated from one of the numerous empirical static equations based on raw milk yield and live weight. It was necessary to correct it by the $\mathrm{AH}$ level to achieve a realistic change of evolution at the onset of lactation. As such this model was only aimed to test the consistency between values of intake, metabolism, milk yield and composition. On this main purpose it provided reasonably satisfactory results of simulation of the major metabolic events of the lactation.

As bST is considered as the major homeorhetic hormone, it was an interesting challenge to assess mechanistic HR models of lactating ruminant through experimental data of bST treatments. Baldwin and Bauman (1984), Baldwin et al (1987), Danfaer (1990) have effectively performed this procedure of validation. The advantage of the RS of the Danfaer's model is that it included plasma [GH] as a driven parameter which can be directly influenced by bST injections. Danfaer (1990) reported that he observed fairly satisfactory metabolic and milk yield responses of his model to simulated bST injections.

Interactions between $H S$ and $H A$ regulations.

Nutrient utilisation and partition are simultaneously driven by $\mathrm{HS}$ and HR influences. It is therefore important to have a quantitative knowledge and representation of the relationships and interactions between them. This constitutes the first step to connect models of $\mathrm{HR}$ and $\mathrm{HS}$ in the framework of whole animal models.
HS regulations can be altered by $H R$ status. Several experimental data (Weekes, 1989; Sleiman et al, 1993) have shown that efficiency of $\mathrm{HS}$ in driving the metabolic pathways depended on the production level or on the energy balance. HS regulations appear thus to be limited or precluded by HA when production level is higher. The phenomenon called insulin resistance, already documented by numerous authors, is an illustration of this limitation. Figure 5 summarizes the influence of the level of production on the relative role of $\mathrm{HR}$ and $\mathrm{HS}$ in driving the metabolism. Nevertheless, the issue is remaining to know if this interaction between HS and HR appears in relative, as in Figure 5 , or in absolute values at the level of nutrients flows. The data obtained by Debras et al (1989) with euglycemic clamps on lactating goat are supporting the principle of additivity (Figure 6). The corresponding equations could be the heart of a model including $H R$ and $H S$ influences on glucose metabolism in lactating goat, or even lactating cow with an appropriate size factor. However, the reality is much more complicated. Effectively the conceptual representation in Figure 5 is valuable for a mean time, for instance 24 hours. Moreover, within the nycthemere there are large variations between the relative influences of $\mathrm{HS}$ and $\mathrm{HR}$ which can

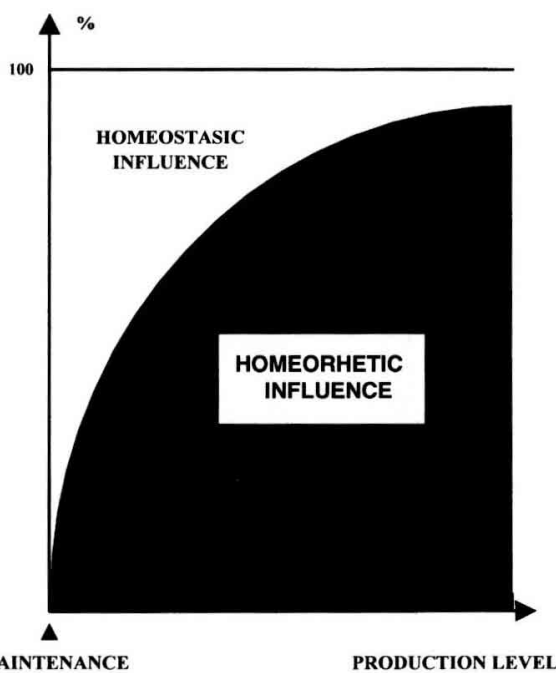

Figure 5. Balance between homeostatic and homeorhetic influences according to the level of production. 


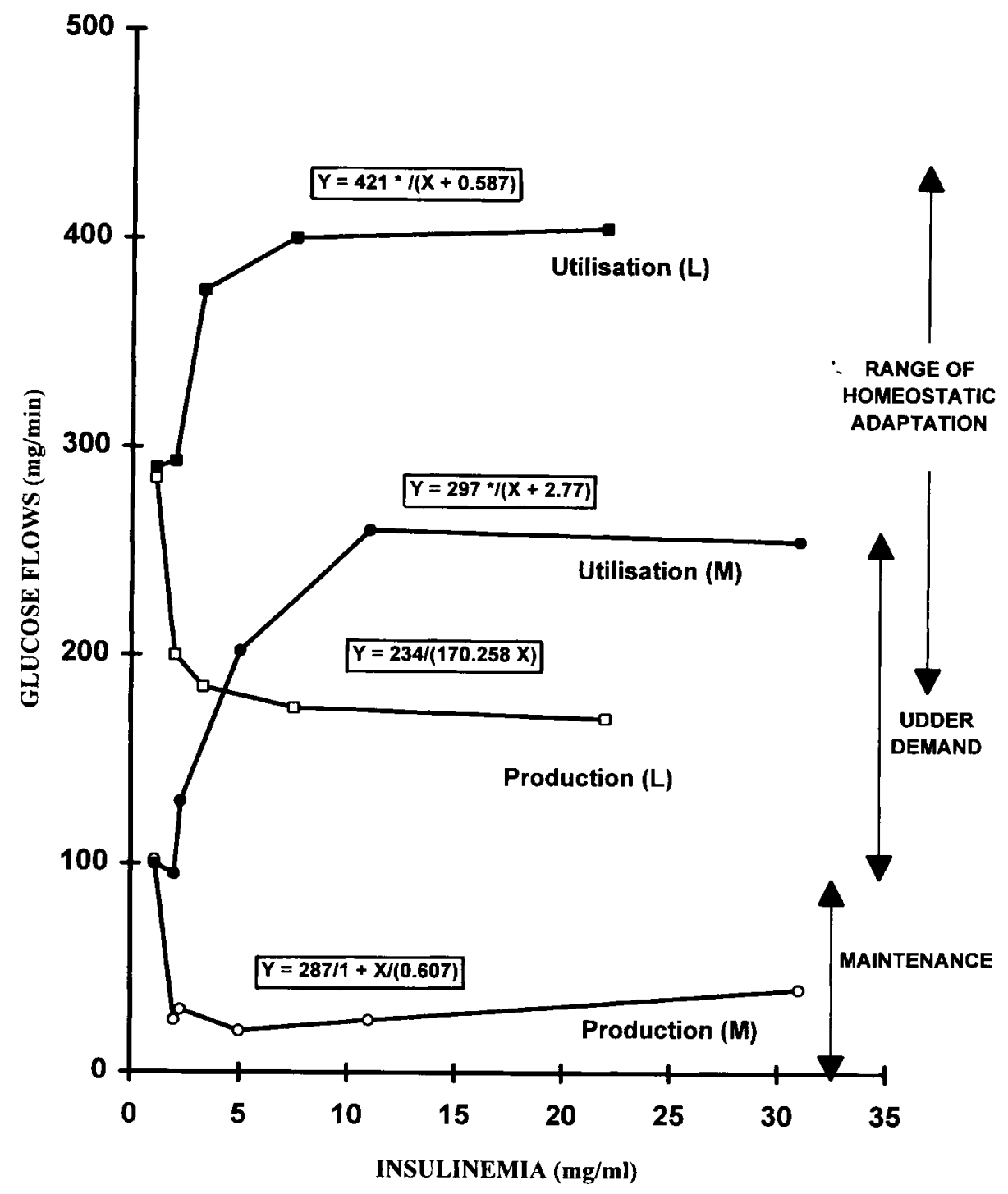

Figure 6. Homeostatic response of hepatic glucose metabolism in goat at maintenance (M) or lactating (L) (Grisard and Aina, 1990). 
be linked to the instantaneous energy balance. As far as we are aware, no model of whole lactating ruminant has been until now targeted to simulate that point.

Reciprocally HR effects can be altered by HS status. HS has a limited capacity to support a period of nutrient shortage. Therefore, if this capacity is exceeded there is an apparent "break of homeorhesis" and the level of synthesis of milk constituents is then drastically decreased. Figure 7 recalls an historical illustrative work of Brody (1952) showing clearly that when a lactating cow is fasted the milk constituents secretion is abruptly decreased. However it is important to stress that this decrease largely differed depending on the milk constituent. Thus the fat secretion is much less altered than the lactose one. These differences are the results of the better efficiency of lipidic than glucidic homeostasis in supporting the homeorhetic demands when the organism is in a situation of shortage of nutrient. This principle could appear as an evidence, although the way to create a mechanistic model to rank the efficiencies of the homeostatic ability of the main metabolic routes supporting milk synthesis has not been yet performed. Such a task would also have to be realised to reach for example the target of simulating some nutritional disorders (ketosis, parturient hypocalcemia...).

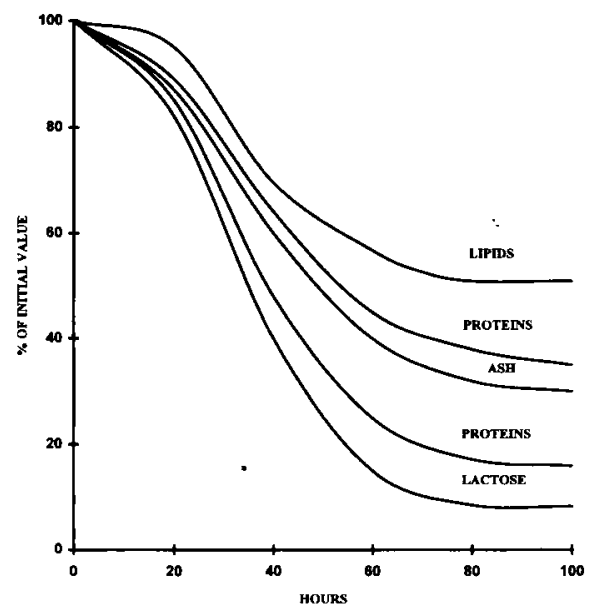

Figure 7. Influence of fasting on the mammary secretions of the cow.

\section{Discussion on modelling metabolic compartments and flows}

A systematic and exhaustive review of all the features dealing with modelling metabolism of lactating ruminant cannot be performed into one report. Therefore only few aspects which offered large discrepancies between models will be focused here.

\section{The blood circulating system}

The role of the blood circulating system in lactating ruminant models has been largely neglected despite it has likely a large influence on nutrient partition through the organism. As far as we are aware, only the cow model of Paul (1990) has attempted to consider some of the roles of the blood circulating system. However the validation of this original part of Paul's model remains today limited. As a consequence of progresses in blood flow experimental measurements, it can be expected that the next generation of whole lactating ruminant models will largely integrate blood flow. One of the major difficulty of these future models will likely be to simulate the short term regulations of blood flow variations (i.e. post prandial period).

\section{Approaches per organ/tissue}

The organs of the splanchnic system:

Numerous data on flows of blood and nutrients passing through the splanchnic organs were published during the last years. Therefore several authors have already elaborated empirical models to predict these flows from diet characteristics or animal parameters (Lindsay, 1993; Ortigues and Visseiche, 1995; Reynolds, 1995; Lescoat et al, 1996). These models will permit to update the systems of predicting responses of the nutrient flows disappearing from the gut rumen.

Mechanistic modelling of splanchnic tissue metabolism seemed until now limited to liver metabolism (Danfaer 1990, Paul 1990, Freetly et al 1993). These 3 liver models contained respectively 13,17 and 23 metabolic compartments. The opportunity to use such detailed model of liver metabolism into a daily based model of lactating ruminant is questionable. This does not seem necessary if the purpose is to simply simulate the HR influences on lactation. Thus the models of Baldwin et al (1987), as its recent version 
(Baldwin, 1995), and Sauvant et al (unpublished) largely used stretched flows to represent the liver metabolism. There was no compartment for Baldwin et al (1987), and only a liver fat compartment for Sauvant et al (unpublished). For short term purpose, it could be valuable to take into consideration two other compartments : the glycogen and labile proteins.

\section{Protein tissue \\ Two protein tissues, viscera and carcass ones, were used in the Baldwin's model while only one aggregated compartment was taken into account in the other models. However it was necessary to add a compartment of uterine protein to ensure, with a high involution-rate, to sustain the tremendous milk protein output at the onset of lactation (Sauvant et al, unpublished). If the target of future model would be to study the contributions of the main organ to amino acids exchanges it would be necessary to distinguish organs, or groups of organs, according to their protein turn over rate and to their profile of amino acid uptake and release (Lescoat et al, unpublished).}

\section{Adipose tissue}

The central dymanic role of adipose tissue in the energy nutrition of lactating ruminant has been well documented. Only one aggregated compartment of adipose tissue was considered in the lactating ruminant models. The metabolic structure of the adipose tissue is quite close between these models. They all represent a simplified metabolic system of the adipocyte. The number of compartments taken into account in the adipose tissue varied from one model to another. It was equal to 3 for Baldwin et al (1987), 6 for Danfaer (1990), 13 for Paul (1990) and 1 for Sauvant et al (unpublished). Furthermore Miller (1995) presented a detailed study of the metabolic intrinsic properties of adipose tissue with a 18 metabolic compartments model.

A particular point that has to be underlined in a whole animal model perspective is the variations of the balance between the 2 anabolic pathways supporting fatty acid synthesis and storage : short precursors (acetate) or preformed fatty acids (from circulating TG and NEFA). Simulations that we have performed (Sauvant et al, unpublished) suggested that this balance is a very sensitive parameter to simulate the low milk fat syndrome. Baldwin et al (1987) already stated that these 2 routes does not present the same sensitivity to variations of glycemia. In our work, it was necessary to use a parameter of partition of flows between these two routes. This parameter was a simple Michaelis-Menten function of plasma acetate concentration. It allowed to highly increase the adipose tissue uptake of $\mathrm{C}_{2}$ and $\mathrm{C}_{4}$ chain acids when the diet was rich in concentrate. A complementary observation to our simulation was reported by Mc Namara and Baldwin (1995). These authors also emphasized the lack of consistency that can be observed between in vitro enzyme activities and whole animal data.

\section{Udder}

A first mechanistic model of mammary gland metabolism was published by Waghorn and Baldwin (1984). A much more complete model of isolated udder (32 compartments) was built by Hanigan and Baldwin (1994). Furthermore a more aggregated udder model integrating blood flows and milk precursor uptake was proposed by Cant (1995). In the whole lactating cow published models the mammary metabolism was highly aggregated and largely corresponded to stretched flow structures. Then the udder was more or less considered as a sink in a quasi steady state situation. This is particularly the case of the model of Baldwin et al (1987) and Sauvant et al (unpublished), while models proposed by Danfaer (1990) and Paul (1990) have respectively considered 8 and 13 compartments in their udder sub part. However these authors did not demonstrate the necessity to use these numbers of mammary compartments in a whole animal model. One major issue arising when mammary metabolism is modelled is the way to integrate the origin and the sense of the driving forces of this metabolisms (see the "push" and "pull" hypothesis).

\section{Approaches per metabolic areas (carbohydrate metabolism excluded)}

\section{Nitrogen metabolism}

Knowledge on amino acid feature has rapidly increased for lactating ruminant during the last decade. It has been shown that some essential amino acids, at least lysine and methionin, could be limiting factors of milk protein secretion (Rulquin et al 1993). It becomes therefore a challenge to improve on this aspect 
the published lactating cow models which had until now just considered amino acids in a unique pool. This task is a priori complicated because of the number of amino acids, of their metabolic specificities and of their mutual interactions. Moreover, the peptides could also play a non negligible role.

The current context of controlling the flows of faecal and urinary $\mathrm{N}$ excretion in numerous areas of the world stressed the need of having a reliable model of the $\mathrm{NH}_{3}$ and urea metabolism of ruminant. Interesting quantitative data have been published on this aspect for several decades (Harmeyer and Martens, 1980), and a first model of $\mathrm{NH}_{3}$-urea metabolism in sheep has been performed two decades ago (Nolan, 1975). The whole dairy cow models included parts of the $\mathrm{NH}_{3}$-urea metabolism. In the model of Baldwin et al (1987) there was only one urea pool which appeared as a compartment of accumulation after amino-acid desamination. In the recent version of this program (Baldwin 1995) urea was synthesized from amino-acid desamination and $\mathrm{NH}_{3}$ metabolization. In this case, the outflow of urea from the blood followed a simple mass-action law. In the model of Danfaer (1990) the structure of the $\mathrm{NH}_{3}$-urea system was fairly comprehensive. The rate of urea excretion in the urine was calculated as the difference between the total urea flux rate produced by the liver and the urea uptake by the rumen and the lower gut. These two last flows were assumed to follow a mass-action law. Several simulations of the Danfaer's model were presented, however this model did not seem to have been precisely assessed through experimental data on this feature. The most detailed model of $\mathrm{NH}_{3}$-urea metabolism was published by Paul (1990), however the issue is remaining on the practical opportunity to achieve this level of detail in a whole animal model.

For HR models it can be stated that $\mathrm{NH}_{3}$ urea metabolism is now fairly well modelled. However blood flows will have to be taken into account to integrate new features which were until now ignored (i.e. the high portal flow of $\mathrm{NH}_{3}$ ).

Lipid metabolism

A first model of lipid metabolism in dairy cow has been described by Baldwin and Smith (1971). Although incomplete according to current knowledge on lipid metabolism during lactation, this model already put in evidence the limit of some in vitro data to model the whole animal lipid metabolism. Three topics of interest for modelling purposes of lipid metabolism have been here selected. They are focused on aspects linked to lipomobilisation : the non esterified fatty acids (NEFA) metabolism, the fatty infiltration of liver, the milk fatty acid secretion.

NEFA flux ranges from about 2.0 to 15.0 $\mathrm{mol} / \mathrm{d}$ in lactating cow (Mc Dowell et al, 1987, Bauman et al 1986). The corresponding flows of energy represent from 4.8 to $36 \mathrm{Mcal} / \mathrm{d}$, or approximately 0.6 to 4.2 times the maintenance energy requirements. For lactating goat and sheep the relative NEFA flux presents the same order of magnitude for a comparable energy status (Pethick and Dunshea, 1993). This meaningful contribution of NEFA to energy metabolism is allowed by their high turnover rate (half life lower than $10 \mathrm{~min}$.). Moreover it has been frequently shown that plasma NEFA content can be, under standardized conditions a relevant index of lipomobilisation and energy balance in cow, goat and ewe. Despite this interest, the NEFA has been almost ignored, because integrated with circulating triglycerides (TG), in the models of Baldwin et al (1987), Danfaer (1990). A distinct NEFA compartment was included in the model of Sauvant et al (unpublished). In this model, the pattern of NEFA plasma concentration during lactation was satisfactorily simulated. However Figure 8 shows that this model tends currently to underestimate the NEFA flux for a given level of NEFA plasma concentration.

In lactating ruminant, nutrition around parturition is characterized by an intense lipomobilisation and therefore a high risk of metabolic disease. A major consequence of this high lipomobilisation is that liver accumulates lipids, largely under the form of TG. As the published models seemed to have neglected this phenomenon of steatosis our attention was focused on it (Sauvant et al unpublished). Liver steatosis was simulated by creating a compartment of liver TG and assuming that inputs (NEFA esterification) were proportional to the size of the NEFA circulating compartment while outputs (lipotropy) followed a mass action law of liver TG storage. This model simulated reasonably the known influences of the lactation stage on liver steatosis (Figure 9). Moreover liver 
steatosis and plasma NEFA contents were positively related. However the level of liver steatosis reached at a given plasma NEFA content was overestimated with this model.

Some human diseases in industrial countries have led to focus the attention on fatty acid (FA) composition of animal fat. Nevertheless the published lactating cow models have ignored this aspect, milk fat being considered as an homogeneous substance. Therefore we have performed an attempt to model milk fat synthesis by distinguishing only 3 main groups of fatty acids was made:

- the $\mathrm{C}_{4}$ to $\mathrm{C}_{14}$ chains of $F A$ which are issued from a mammary synthesis from $\mathrm{C}_{2}$ and $\mathrm{C}_{4}$ precusors.

- the $C_{18}$ chain $F A$ which are taken up from the circulating TG and NEFA.

- the $C_{16}$ acid which is assumed to be issued at 50-50 from the two previous origins.

Despite its high simplicity this model provided realistic patterns of milk FA secretion and composition at the onset of lactation (Figure $10)$. Furthermore it would be necessary to include additional aspects (individual levels of synthesis of the 10 to 12 main FA, inhibition of the endogenous FA synthesis by the long chain FA availability in the secretory cells...) to simulate more precisely the known variations of milk fat composition.
Oxidative metabolism

An important challenge in modelling oxidative metabolism in lactating ruminant is to permit substitutions between the contribution of the main nutrients to the whole oxidative flow. They constitute a key mechanism to spare essential nutrients in specific physiological situations (i.e. glucose at the onset of lactation) and to ensure a better metabolic flexibility. In the model of Baldwin et al (1987) and in the Mollys'one (Baldwin, 1995) a certain level of substitution was allowed between oxidized nutrients that were glucose, acetate and fatty acids. The flow rates of oxidation was determined to cover the ATP requirements of the various tissues. For acetate and fatty acid these flows were assumed to obey a single substrate Michaelis-Menten form. For glucose the value of the constant of Michaelis was a function of the anabolic hormones which allowed to increase the glucose oxidation in case of high glycemia. However in this model, ATP was considered as a zero pool and there was therefore no retroactive possibility of control of catabolic pathways by a parameter such as the adenylic ratio.

The oxidative metabolism was not taken into consideration in the models of Danfaer (1990) and Sauvant and Phocas (1993). In contrast the model of Paul (1990) presented a detailed

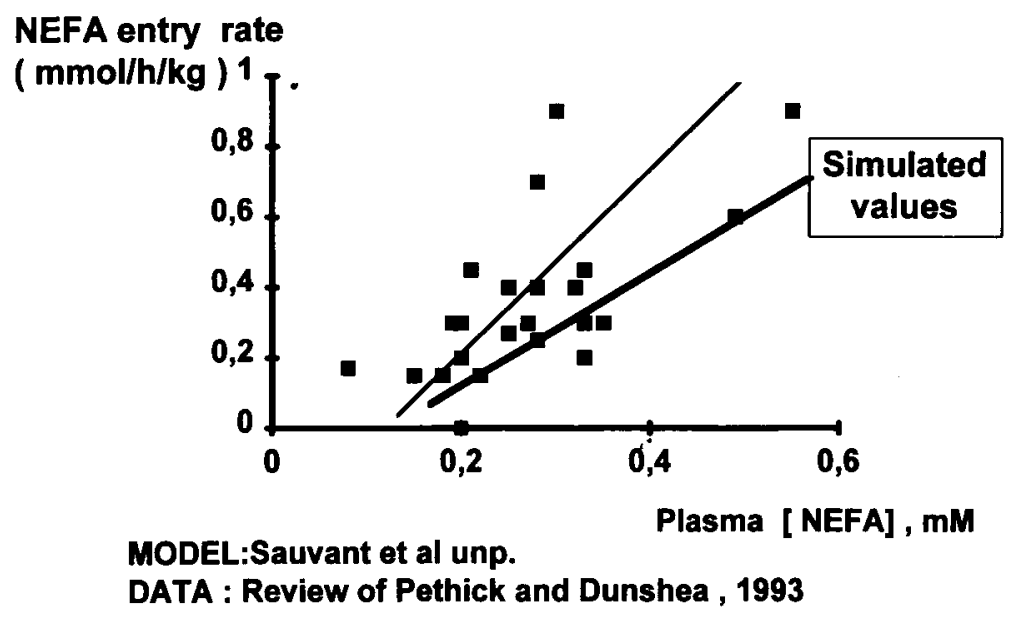

Figure 8. Simulation of NEFA entry rate and concentration. 


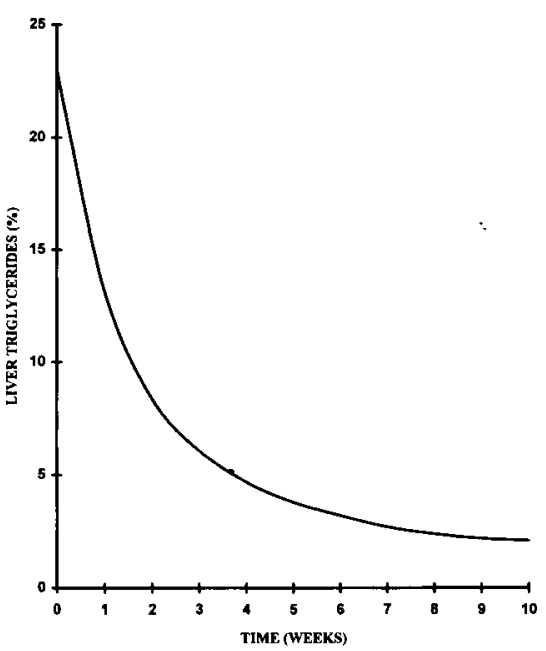

Figure 9. Simulation of the liver steatosis according to the lactation stage.

description of ATP formation along numerous metabolic pathways and for the major organs. The oxidative part of this model (ATP formation and utilization, $\mathrm{O}_{2}$ respiration, heat production) allowed to simulate short term variations of these parameters. It must be emphasized that this model went yet further in this area by including basic features of thermoregulation.

\section{Minerals}

Historically the first attempts to model animal or human nutrition were consecrated to mineral metabolism (Christiansen et al, 1924). This was a consequence of the possibility to investigate mineral metabolism with labelled elements. Some interesting models have been done further. Sulfur metabolism was modelled in sheep by Kennedy and Milligan (1978). Schneider et al (1987) have proposed a model of $P$ metabolism in sheep. Recently Symonds and Forbes (1993) described the basis of models of $\mathrm{Cu}$ and $\mathrm{P}$ metabolism in sheep.

Taking into consideration that minerals are frequently essential nutrients for lactation and that they can contribute to nutritionnal disorders and also to pollution processes it seems urgent to increase the modelling efforts on this area. For the major mineral elements a rapid survey of literature allows to distinguish in this area as well short term and long term variations and regulations of the metabolism. Therefore models aimed at this topic will likely have to integrate these both regulatory features.

\section{From cow to goat and ewe models ?}

Until now published mechanistic models of lactating ruminant have only dealt with dairy cows. Research has largely demonstrated the high level of similitude of physiological and

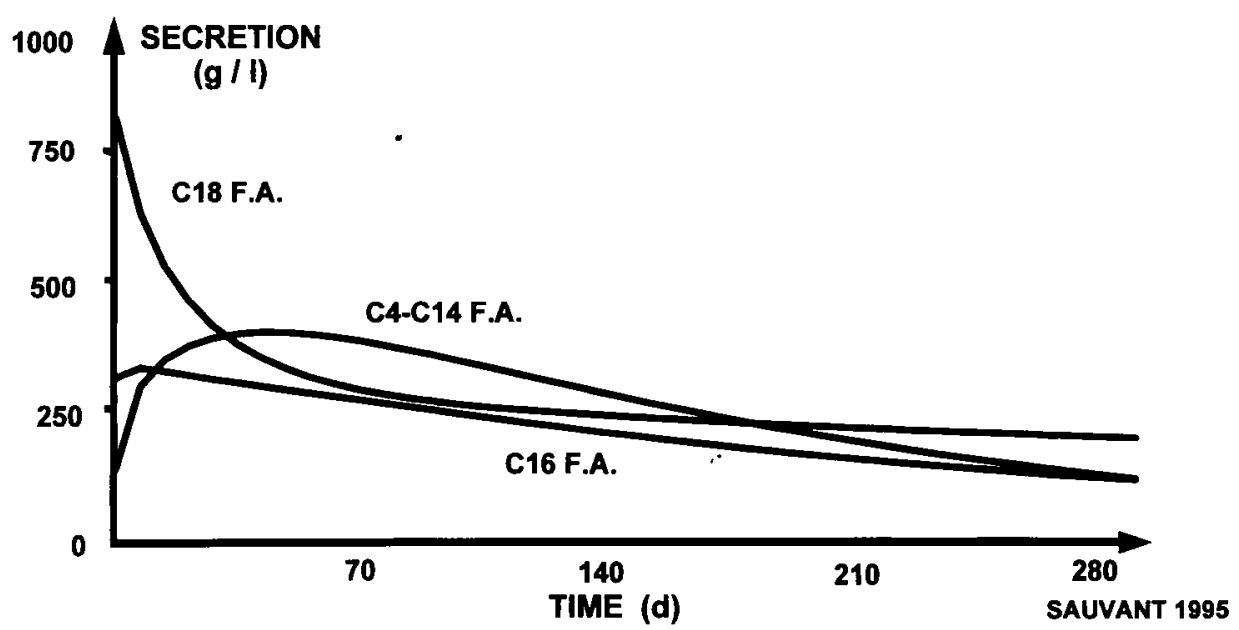

Figure 10. Simulated patterns of milk fatty acids in lactating cow whose peak milk production is $30 \mathrm{~kg}$. 
nutritionnal processes between the various types of lactating ruminants. Therefore it seemed logical to try to convert models obtained on one species to another one. We tried to perform simply such a conversion from the lactating cow to lactating goat. For that the sizes of all the key compartments or fluxes were divided per 10 . For the regulating subsystem it was assumed that the value of the potential POT was also divided by 10 . It appeared necessary to alter the values of a milk composition parameters to be representative from the goat values:

the milk lactose content was decreased from 48 to $43 \mathrm{~g} / \mathrm{l}$.

-the uptake rate by the udder of precursors of milk fat and protein must be multiplied by the factor 0,7 to achieve goatty values of milk fat and protein contents.

With these corrections, we have simulated various situations and validated the goat model against several experimental data bases of our laboratory. Results of validations were fairly satisfying. As an example, Figure 11 shows the validation of intake and energy balance patterns at the onset of the lactation. However if this first attempt to transfer a cow model to a goat one can be judged as satisfying it is important to keep in mind that known specific features of discrepancy between these both species were currently neglected. This is for example the case of the acute behaviour of diet selection of the goat.

As far as we are aware, model transfer from cow to ewe has not been published. The interesting data that we obtained with the transfer from cow to goat invites to go further in the comparative nutrition studies between various lactating ruminant species through mechanistic modelling. Applied nutrition research can effectively expect large advantages (scientific, economic...) from doing, by modelling, more systematic transfers of experimental data from one species to another. Advantages can also result is studying systematic and specific differences which could appear from assessing a given model through various species. Such a method was already applied to have an idea of the level of universality of the relationship linking plasma urea content and urinary $\mathrm{N}$ ouflow in cow, goat and sheep (Sauvant, 1993).

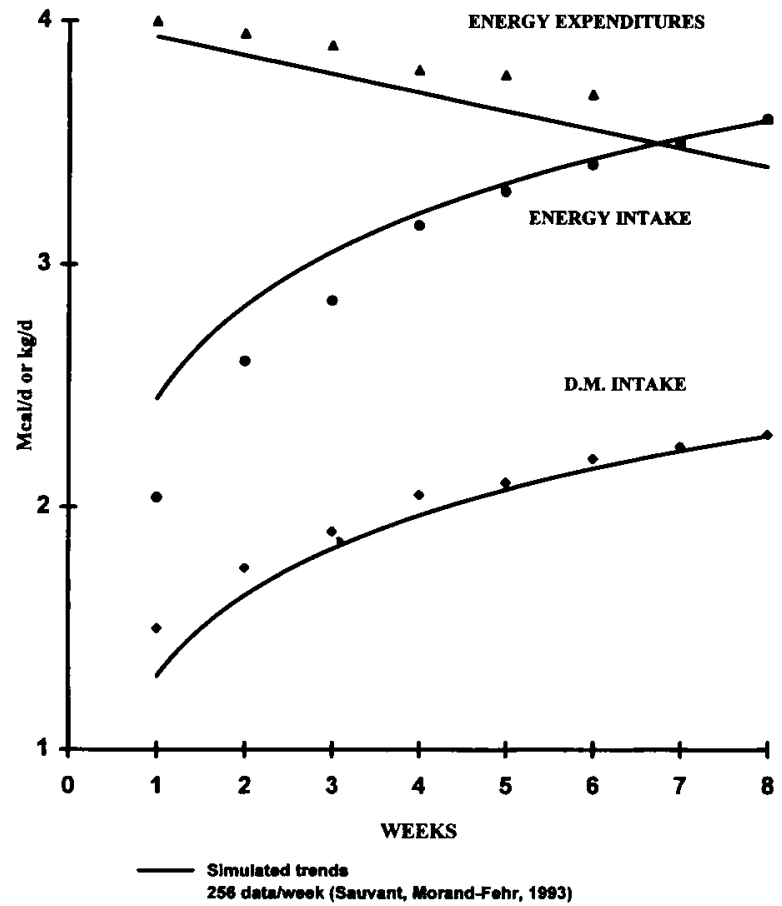

Figure 11. Simulation of kinetics of intake of dry matter and energy and expenditures of energy in dairy goat at the beginning of lactation. 


\section{Conclusions}

Whole lactating ruminant models provide a convenient framework to integrate and to assess punctual data or empirical equations dealing with underlying physiological functions. In our case, the integration of empirical equations of literature aimed at the same target, allowed to observe large differences between simulated data for poorly known (VFA flows) as well as for common (rumen volume) parameters.

Despite the great progresses of the recent years tremendous work remains to be done before having a mechanistic model of lactating ruminant which could combine simplicity and ability to simulate all the main responses to the diet variations. The major areas or issues which are requiring specific efforts are, without ranking :

-the connection between digestive and metabolic submodels and intake regulation; -the production and absorption of VFA in the reticulorumen and in a lesser extend the flows of absorption of other nutrients;

-as knowledge is much more advanced on the operating than on the regulating subsystem an actual priority will have to be done on modelling regulations involved in lactation. The principle of the theoretical regulating subsystem, involving linked anabolic and catabolic influences, seems to be a sound basis which will not be contested although meriting a more precise description and flexibility. Otherwise we are convinced that the distinction between homeostatic and homeorhetic drives will be useful to structure the knowledge and to progress, as did the concept of maintenance and production requirements;

-the regulations will have to be carefully modelled in the area of energy (lipids and carbohydrates) metabolisms. This could be performed through the aim of understanding and predicting the milk fat content responses to its known numerous causes of variation;

-the building of an amino acid submodel and the possibility to simulate the main mechanisms involved in milk protein content variations;

-the development of a submodel of mineral metabolism;

-the determination of sets of parameters or submodels which needs specific modifications when transferring a model from one type of lactating ruminant to another.

Acknowledgement to $P$ Lescoat for his relevant remarks on this text.

\section{Literature cited}

AFRC (1992) Nutritive requirements of ruminant animals: protein. Nut Abst Rev 62

Archimède $H$, Sauvant $D$, Schmidely $P$ (1996) Ruminal and total tract digestion of mixed diet organic matter and carbohydrates, a quantitative review. Reprod Nutr Dev (in press)

Baldwin RL, (1995). Modeling ruminant digestion and metabolism. (Chapman, Hall, eds) $566 \mathrm{p}$

Baldwin RL, Cabrera R (1970) Energetic relationship in the formation and utilization of fermentation end products. In: Physiology of digestion and metabolism in the ruminants. (AT Philipson, ed) Oriel press, $319 p$

Baldwin RL, Baumann DE (1984) Partition of nutrients in lactation. In : Proc 2nd int Workshop on modeling ruminant digestion and metabolism (Baldwin, Bywater, eds) Davis (USA), 80-88

Baldwin RL, Smith NE (1971) Intermediary aspects and tissues interactions of ruminant fat metabolism. J Dairy Sci 54, 583-595

Baldwin RL, Thornley JHM, Beever DE (1987) Metabolism of the lactating cow. If Digestive elements of a mechanistic model. J Dairy Sci 54 , 107-131

Bannink A, de Visser M (1995) Comparison of mechanistic rumen models on mathematical formulation of extramicrobial and microbial processes. J Dainy Sci (in press)

Bauman DE, Currie WB (1980) Partitioning of nutrients during pregnancy and lactation: a review of mechanisms involving homeostasis and homeorhesis. J Dairy Sci 63, 1514-1525

Bauman DE, Pell CJ, Steinhow WD, Reynolds PJ, Tyrell HF, Brown ACG, Haaland GL (1988) Effects of somatotropin on metabolism of lactating cows : influences on rates of irreversible loss and oxidation of glucose and NEFA. J Nutr 118, 1031-1040

Beleya RL, Frost GR, Martz FM, Clark JL, Forkuev LG (1978) Body composition of dairy cattle by potassium. 40 liquid scintillation detection. $J$ Dairy Sci 61, 206-211.

Bosh M (1991) Influence of stage of maturity of grass silages on digestion processes in dairy cows. thesis, univ Wageningen

Brody S (1952) Bioenergetics and growth. (Hafner, ed) Press, $1015 p$ 
Cant JP (1995) Modelling uptake of blood metabolites by the mammary gland of a lactating cow. In: Modelling Nutrient Utilisation in Farm Animals (A Danfaer, $P$ Lescoat, eds) Foulum (DK), 53-89

Chilliard Y, Robelin J (1985) Activité lipoprotéine lipasique de différents dépôts adipeux et ses relations avec la taille des adipocytes chez la vache tarie en cours d'engraissement, ou en début de lactation. Reprod Nutr Dev 25, 287-293

Christiansen LA, Hevesey G, Lomholt S (1924) Recherche par une methode radiochimique sur la circulation du bismuth dans l'organisme. CR Acad Sci Paris 178, 1324-1326

Danfaer A (1990) A dynamic model of nutrient digestion and metabolism in lactating dairy cows. $n^{\circ} 671$, Beretning, Foulum (DK), 511p

Debras E, Grizard J, Aina J, Tesseraud S, Champredon C, Arnal M (1989) Insulin sensitivity and responsiveness during lactation and dry period in goats. Am J Physiol 256, 295-302

Dijkstra J, Neal HD, Beever DE, France J (1992) Simulation of nutrient digestion absorption and outflow in the rumen: model. J Nutr 122, 22392256

Dijkstra J, Boer $\mathrm{H}$, Van Bruchen J, Bruining $M$, Tamminga $S$ (1993) Absorption of volatile fatty acids from the rumen of lactating dairy cows as influenced by VFA concentration and rumen liquid volume. Br J Nutr 69, 385-396

Dijkstra J, France J (1995) A comparative evaluation of models of whole rumen function. in: Modelling Herbivore Nutrition, Satellite of the $I^{\text {th }}$ Symp Nutr Herb, Paris 1995

Doreau M, Ferlay A (1994) Digestion and utilisation of fatty acids by ruminants. Anim Feed Sci Technol 45, 379-396

Faverdin P, Hoden A, Coulon JB (1987) Recommandations alimentaires pour les vaches laitières. Bull Tech CRZV-INRA 70, 133-152

Freetly HC, Knapp JR, Calvert CC, Baldwin R (1993) Development of a mechanistic model of liver metabolism in the lactating cow. Agric Syst 41, 157-195

Forbes JM (1995) Voluntary food intake and diet selection in farm animals (Forbes, ed) $\mathrm{CAB}$ international, $532 \mathrm{p}$

Goldbeter A (1990) Rythmes et chaos dans les systèmes biochimiques et cellulaires. Masson ed, $301 \mathrm{p}$

Hanigan MD, Baidwin RL (1994) A mechanistic model of mammary gland metabolism in the lactating cow. Agric Syst 45, 369-387.

Harmeyer J, Martens $H$, (1980), Aspects of urea metabolism in ruminants with reference to the goat. J Dairy Sci 63, 1707-1728

Herbein JH, Biello RJ, Eckler LI (1985) Glucagon, insulin, growth hormone and glucose concentrations in blood plasma of lactating dairy cows. J Dairy Sci 68, 320-345

Kohn RA, Boston RC, Ferguson JD, Chalupa W (1995) The intregation and comparison of dairy cow models. In: Modelling Nutrient Utilization in Farm Animals (A Danfaer, P Lescoat,eds) Foulum (DK) 117-128

Lescoat P, Sauvant D (1995) Development of a mechanistic model for rumen digestion validated using the duodenal flux of amino acids. Reprod Nutr Develop 35, 45-70

Lescoat P, Danfaer A, Sauvant D (1996) Quantitative aspects of blood and amino acid flows in cattle. Repro Nutr Dev elop36, 137-174

Lindsay DB, (1993), Metabolism of the portai-drained viscera. In: Quantitative aspects of ruminant digestion and metabolism (Forbes, ed) France, 267-289

Madsen J (1985) The basis of the proposed nordic protein evaluation system for ruminants; the AAT-PBV system. Acta Agric Scand 25, 9-20

Mc Dowell GH, Hart IC, Bines JA, Lindsay DB, Kirby AC (1987) Effects of pituitary derived bovine growth hormone on production parameters and biokinetics of key metabolites in lactating dairy cows at peak and mid lactation. Aust $J$ Biol Sci 40, 191-202

McNamara JP, Baldwin RL (1995) Modelling metabolism in lactation: estimation of critical parameters in lipid metabolism. In: Modelling Nutrient Utilisation in Farm Animals, (A Danfaer, $P$ Lescoat, eds) Foulum (DK), 63-85

Miller PS (1995) Dynamic models of ruminant adipose tissue metabolism. In: Modelling ruminant digestion and metabolism (Chapman, Hall, eds) 319-369

Monod J (1970) Le hasard et la nécessité. Ed Le Seuil, $213 p$

Murphy MR, Baldwin RL, Koong LJ (1982) Estimation of stoichiometric parameters for rumen fermentation of roughage and concentrate diets. $J$ Anim Sci 55, 411-421

Neal HD, Thornley JHM (1983) The lactation curve in cattle: a mathematical model of mammary gland. $J$ Agric Sci Camb 101, 389-44

Nolan JV (1975) Quantitative models of nitrogen metabolism in sheep. In: Digestion and Metabolism in the ruminant (IW Mc Donald, AR Warner, eds) 416-431

O'Connor JD, Sniffen CJ, Fox DG, Chalupa W (1993) $A$ net carbohydrate and protein system for evaluating cattle diets IV, Prediction Amino acid adequacy. J Anim Sci 71, 1298-1311

Ortigues I, Visseiche AL (1995) Whole body fuel selection in ruminants: nutrient supply and 
utilization by major tissues. Proc Nutr Soc 54 , 235-251

Paul W (1990) Physiologie der Milchkuh, eine mathematische Systemanlage. Landbauforschung Volkenrode, Sonderheft 116, $290 p$

Pethick DW, Dunshea FR (1993) Fat metabolism and turnover. In: Quantitative aspects of ruminant digestion and metabolism (Forbes, ed) France, 291-311

Ramangasoavina B, Sauvant D (1993) Comparative validation of 3 models of rumen digestion to predict the duodenal microbial $\mathrm{N}$ flows. Ann Zootech 42, 164-165

Remond B (1988) Evolution du poids du contenu du réticulo-rumen chez les vaches laitières au cours des deux premiers mois de la lactation. Reprod Nutr Develop 28, 109-110

Reynoids CK (1995) Quantitative aspects of liver metabolism in ruminant. In: Ruminant Physiology: Digestion, Metabolism, Growth and Reproduction (Engelhart et al, eds) 351-371

Rulquin H, Pisulewski PM, Verité R, Guinard J (1993) Milk production and composition as a function of post ruminal lysine and methionine supply: a nutrient reponse approach. Livest Prod Sci 37 , 69-90

Sauvant D (1992) La modélisation systémique en nutrition. Reprod Nutr Develop 32, 217-230

Sauvant D, Baumont R, Faverdin P (1996) Development of a mechanistic model of intake and chewing activities of sheeps. J Anim Sci (in press)

Sauvant D, Grizard J (1992) Bases d'un modèle décrivant la régulation du métabolisme du glucose de la chèvre en lactation. Ann Zootech $41,115-116$

Sauvant D, Phocas F (1993) A mechanistic model to simulate the long term regulation of the dairy cow nutrition. J Dairy Sci 75, suppl 168

Sauvant D (1993) Basis of a mechanistic model of exchange between ammonia and urea compartment in ruminant. Ann Zootech 42 , 202-203

Sauvant D, Chapoutot $P$. Archimède $H$ (1994) La digestion des amidons par les ruminants et ses conséquences. Prod Anim 7, 115-124.

Sauvant D (1994) Modelling homeostatic and homeorhetic regulations in lactating animals. Livest prod Sci 39, 105-113

Seal CJ, Reynolds CK (1993) Nutritional implications of gastrointestinal and liver metabolism in ruminants. Nutr Res Rev 6, 185-208

Sleiman HA, Sauvant D, Schmidely P, Bas P (1993) Influence of the milk yield on the energy homeostasis of dairy goats. J Dairy Sci 76, Sup 222

Symonds HW, Forbes JM (1993) Mineral metabolism. In: quantitative aspects of ruminant metabolims (Forbes, ed) France, 363-379

Thivend $P$, Poncet $C$ (1978) Alimentation des Ruminants ( $R$ Jarrige, ed) INRA-Edition, 363-379

Verité $R$, Michalet-Doreau $B$, Chapoutot $P$, Peyraud $\mathrm{JL}$, Poncet $\mathrm{C}$ (1987) Révision du Système des protéines digestibles dans l'intestin. Bull Tech CRZV Theix-INRA 70, 19-34

Vérité R, Peyraud JL (1994) Comparison of the modern protein evaluation systems for ruminants. In: Proceeding of the 3rd int Feed Prod Conf, (Piva, ed) Piacenza, 233-247

Waghorn GC, Baldwin RL (1984) Model of metabolite flux within mammary gland of the lactating cow. $J$ Dairy Sci 67, 531-544.

Weekes TEC (1989) Hormonal control of glucose metabolism, 183-200 in: Proc 7th. Int Symp of Ruminant Physiol (Tsuda, Sasaki, eds) Academic Press, 233-247 